\title{
The ankle brachial index in people with and without diabetes: intra-tester reliability
}

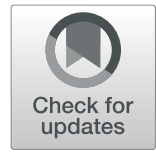

Sarah Louise Casey $^{1^{*}}$ (D) Sean Michael Lanting ${ }^{1}$ and Vivienne Helaine Chuter ${ }^{1,2}$

\begin{abstract}
Background: The ankle-brachial index $(A B I)$ is widely used for determining the presence and severity of peripheral arterial disease (PAD), and current guidelines suggest it should be used to monitor possible progression in affected individuals. It is therefore important that the technique demonstrates adequate reliability for repeated measurements. Existing studies suggest that the $\mathrm{ABI}$ is reliable in the general population however, there is a lack of evidence for the reliability of the $A B I$ in people with diabetes. The aim of this study was to investigate the intratester reliability of the $A B I$ in people with and without diabetes.

Methods: Eighty-five participants (40 with and 45 without diabetes) underwent ankle and brachial systolic blood pressure measurements by a single clinician during two testing sessions. Intraclass correlation coefficients (ICC), their $95 \%$ limits of agreement, standard error of measurement and minimal detectable change were determined.
\end{abstract}

Results: Intra-tester reliability of the ABI was found to be good (ICC: 0.80 ), however sub-group analysis of participants with and without diabetes found that $\mathrm{ABI}$ was slightly less reliable in people with diabetes (ICC: 0.78 ) than in those without (ICC: 0.82). The relatively large limits of agreement ( -0.16 to 0.16$)$, standard error of measurement (0.03 overall, 0.04 for the diabetes group), and minimal detectable change (0.08 overall, 0.11 for the diabetes group) suggest that a large change in $\mathrm{ABI}$ is required for it to demonstrate a true change rather than the result of measurement variability. The minimal detectable change for the ABI was 0.08 overall, and 0.11 for the diabetes group.

Conclusions: The ABI demonstrated good reliability in all groups analysed. However, the wide limits of agreement and considerable standard error of measurement obtained support the use of multiple methods of vascular assessment for ongoing monitoring of lower limb vascular status.

Keywords: Ankle-brachial index, Reliability, Peripheral arterial disease

\section{Background}

Peripheral arterial disease (PAD) is estimated to affect up to $12 \%$ of the general population [1], and up to $14 \%$ of people with diabetes [2]. Characterised by progressive stenosis of the lower limb arteries, the presence of PAD is strongly predictive of morbidity and mortality in people with diabetes [3].

Due to the high risk of concurrent cardiovascular disease, and lower limb complications associated with PAD,

\footnotetext{
* Correspondence: sarah.casey@newcastle.edu.au

${ }^{1}$ School of Health Sciences, University of Newcastle, Ourimbah, Australia

Full list of author information is available at the end of the article
}

and the rapid progression of atherosclerosis in people with diabetes, accurate and reliable diagnostic testing methods are necessary for early diagnosis and effective ongoing monitoring. Early detection of PAD allows for intervention and management of coexisting cardiovascular disease, including lifestyle advice and medication [4, 5], and prevention and management of lower limb complications such as foot ulceration and amputation [6].

The ankle brachial index (ABI) is typically calculated as the ratio of the highest of the dorsalis pedis and posterior tibial artery systolic pressure to the highest of the left and right brachial systolic pressures [7]. A normal value for $\mathrm{ABI}$ assessment within the general population

\section{$\triangle B M C$}

(C) The Author(s). 2020 Open Access This article is licensed under a Creative Commons Attribution 4.0 International License, which permits use, sharing, adaptation, distribution and reproduction in any medium or format, as long as you give appropriate credit to the original author(s) and the source, provide a link to the Creative Commons licence, and indicate if changes were made. The images or other third party material in this article are included in the article's Creative Commons licence, unless indicated otherwise in a credit line to the material. If material is not included in the article's Creative Commons licence and your intended use is not permitted by statutory regulation or exceeds the permitted use, you will need to obtain permission directly from the copyright holder. To view a copy of this licence, visit http://creativecommons.org/licenses/by/4.0/ The Creative Commons Public Domain Dedication waiver (http://creativecommons.org/publicdomain/zero/1.0/) applies to the data made available in this article, unless otherwise stated in a credit line to the data. 
is considered to be $1.00-1.40$ [8], with values $0.91-0.99$ classed as 'borderline', while those below 0.91 represent likely PAD [9]. The ABI is a widely used as a noninvasive method of conducting objective lower limb vascular assessment to monitor at risk patients for the development of PAD [9]. Current international guidelines recommend the $A B I$ be used routinely to monitor for PAD in older people, those with a smoking history and in people with diabetes $[8,9]$.

Due to the requirement for periodic assessments over the long term to identify development, and where relevant, progression of $P A D$, high reliability of the $A B I$ is essential $[7,10]$. There are a number of factors that are recognised to affect $\mathrm{ABI}$ measurement, and, subsequently, its reliability. These include recent caffeine ingestion [11], tobacco use [12] or exercise [13, 14], clinical experience $[15,16]$, as well as measurement procedure including lack of pre-test rest [17] and body position [18] during measurement. Existing studies of ABI reliability are inconclusive, with inconsistencies in methodology, statistical analysis and reporting making interpretation of the findings difficult, particularly when coupled with the lack of data for those without symptoms, but for whom screening is recommended [19]. There are currently little available data quantifying the magnitude of error that occurs with the measurement and therefore the amount of change in ABI that represents a true change (over and above measurement error) [20]. There has also been limited investigation of the intra-tester reliability of the $\mathrm{ABI}$ in people with diabetes, with only one previous study, which reported a coefficient of variation of $8 \%$ [21]. In diabetes cohorts, PAD is known to have a more aggressive disease presentation [22], to be more likely to affect infra-genicular arteries [23] and to co-exist with medial arterial calcification which can prevent compression and pressure measurement of the lower leg arteries [24]. Although there is significant evidence that these factors affect diagnostic accuracy of the ABI in this population, it is unknown the extent to which the presence of diabetes may affect $\mathrm{ABI}$ reliability [25-27]. The primary aim of this study was to determine the intra-tester reliability of the $\mathrm{ABI}$ in adults with and without a diagnosis of type 1 or type 2 diabetes mellitus.

\section{Methods}

This reliability study was undertaken at the University of Newcastle Podiatry Clinic on the New South Wales Central Coast. Ethics approval was obtained from the University of Newcastle Human Research Ethics Committee (H-2010-1230).

\section{Participants}

Participants were recruited on a volunteer basis from the current patient population attending the University of
Newcastle Podiatry Clinic and the local community, via flyer advertising. Informed written consent was given by all participants prior to their participation in this study. Inclusion criteria were in line with the current American Heart Association (AHA) recommendations for PAD screening using resting $A B I$ [9]: 65 years of age and over, or aged 50 years and over with risk factors for atherosclerosis (e.g. diabetes mellitus, history of smoking), or in individuals with exertional leg pain or non-healing wounds. Exclusion criteria were inability to give informed consent, contraindications to brachial and/or ankle pressure measurement including history of deep vein thrombosis, lymphoedema of the arms or legs, history of mastectomy or current leg ulceration preventing placement of a blood pressure cuff around the lower leg, and inability lie in a supine position for $40 \mathrm{~min}$. Participant medical history was obtained through medical records and via self-report.

\section{Equipment}

Systolic ankle pressures were measured using an $8 \mathrm{~Hz}$ Bidop ES-100 V3 hand-held Doppler (Hadeco), an adult standard, adult large or adult extra-large inflatable cuff (Liberty Health Care) and an ERKA sphygmomanometer (Kallmeyer Medizintechnik GmbH and Co). Cuff size was determined in accordance with AHA recommendations for cuff width and length [7]. All blood pressure gauges were newly calibrated.

\section{Procedure}

Data collection was performed at the University of Newcastle Podiatry Clinic. All testing was performed by the same clinician, a Podiatrist with more than 15 years' clinical experience, using ABI several times a week. Participants were asked to avoid alcohol, exercise and caffeine for $1 \mathrm{~h}$ prior to participating in each testing session. Participants attended two testing sessions, with the second session occurring 7-10 days after the first, and at a similar time of day (morning or afternoon). The test procedure was carried out in accordance with the American Heart Association Scientific Statement [7]. Tests were performed in a controlled environment with room temperature maintained at $24-25^{\circ} \mathrm{C}$ via air-conditioning setting. The participant was maintained in a supine horizontal position for $10 \mathrm{~min}$ prior to, and during testing, and was encouraged to rest and not engage in conversation or other activity during the testing process. Blood pressures were measured at the brachial, posterior tibial and dorsalis pedis arteries in both left and right limbs. All blood pressures were measured once, with a minimum of $3 \mathrm{~min}$ between pressure measurements. The order of pressure measurements was determined using a computergenerated random allocation. One limb for each participant was selected at random for inclusion in statistical analysis. The ABI was calculated as the ratio of the higher 
of the dorsalis pedis and posterior tibial systolic blood pressures to the higher of the left or right brachial systolic blood pressures.

\section{Statistical analysis}

Statistical analysis was performed using the Statistical Package Social Science software version 25 (SPSS Inc., Chicago, Illinois). A sample size of a minimum of 40 participants for each group (diabetes and no diabetes) was determined, based on $\alpha=0.5, \beta=0.2$ for two observations per participant, with a target ICC of 0.8 and a lowest acceptable ICC of 0.6 [28]. It was conservatively anticipated there would be a $15 \%$ loss to follow up requiring enrolment of 90 participants. Intra-class correlation coefficient (ICC) estimates and their 95\% confidence intervals (CI) were calculated (Model 3,1) based on a two-way mixed effects model to determine level of agreement between test and re-test for the measured ABI. All ICC values were interpreted according to cut-offs suggested by Portney and Watkins [29],in which $>0.75$ denotes good reliability, 0.50 to 0.75 suggests moderate reliability, and values below 0.50 represents poor reliability. Paired t-tests were performed for the $\mathrm{ABI}$ test and re-test reliability to determine whether a statistically significant difference existed between scores. Measurement error (i.e. the spread of values obtained around the true value) was expressed in the original units using the standard error of measurement, SEM $=\mathrm{SD} * \sqrt{ }(1-\mathrm{ICC})$ and $95 \%$ limits of agreement (LOA) were calculated, 95\% LOA $=$ Mean \pm SD (1.96) [29]. To determine the smallest amount of change that must be achieved to reflect a true change, outside the error of the tests, the minimal detectable change (MDC) was calculated as $\mathrm{MDC}=1.96 * \mathrm{SEM}^{*} \sqrt{ } 2$ [29]. Independent $\mathrm{t}$-tests were performed on mean brachial and ankle pressures and the mean ABI between the group with diabetes and the group without diabetes to determine the existence of statistically significant differences between the two groups. A Chi-square test was used to test for between group differences for categorical variables including smoking history and gender. For the purposes of this study, ABI values of $\leq 0.90$ and $>1.40$ were considered abnormal, with those between 0.91 and 1.40 deemed to be normal.

\section{Results}

Ninety participants were recruited (44 male, 46 female), 45 with diabetes. Of those recruited 5 participants (4 males, 1 female, all with diabetes) were unable to attend follow-up testing on the correct day or time and were excluded from the analysis. Eighty-five participants attended both sessions ( 40 male, 45 female), 40 with diabetes. The mean age of participants with diabetes was 68 years ( $\mathrm{SD} \pm 7.3$ years), and 76.3 years ( \pm 7.4 years) for those without. Mean BMI for those with and without diabetes was $33.9 \pm 5.4$ and $29.4 \pm 3.9$ respectively. Participant characteristics are described in Table 1. There was no significant difference between the number of participants with a history of smoking, or between the gender distribution in those with and without diabetes.

There was no statistically significant difference between mean ankle pressure, mean brachial pressure or mean $\mathrm{ABI}$

Table 1 Participant characteristics

\begin{tabular}{|c|c|c|c|}
\hline & Diabetes $(\boldsymbol{n}=40)$ & No diabetes $(\boldsymbol{n}=45)$ & Between group differences \\
\hline Males n (\%) & $20(50)$ & $20(44)$ & 0.79 \\
\hline Females n (\%) & $20(50)$ & $25(55)$ & \\
\hline Age range (years) & $50-81$ & $65-94$ & \\
\hline Mean age (years) & 68.0 & 76.3 & 0.001 \\
\hline Mean body mass index & 33.9 & 29.4 & 0.001 \\
\hline Smoking history $\mathrm{n}(\%)$ & $16(40)$ & $15(33)$ & 0.94 \\
\hline Mean diabetes duration (years) & 8.1 & & \\
\hline Oral hypoglycaemics n (\%) & $31(78)$ & & \\
\hline Insulin n (\%) & $14(35)$ & & \\
\hline Neuropathy n (\%) & $14(35)$ & & \\
\hline Mean ankle pressure $1 \mathrm{mmHg}$ (SD) & $129.9(15.5)$ & $132.7(11.8)$ & 0.22 \\
\hline Mean ankle pressure $2 \mathrm{mmHg}(\mathrm{SD})$ & $132.5(16.1)$ & $127(12.6)$ & 0.65 \\
\hline Mean brachial pressure $1 \mathrm{mmHg}$ (SD) & $123.6(11.4)$ & 130.9 & 0.22 \\
\hline Mean brachial pressure $2 \mathrm{mmHg}$ (SD) & $124.7(11)$ & 129.5 & 0.10 \\
\hline Mean $\mathrm{ABI}$ test $1 \mathrm{mmHg}(\mathrm{SD})$ & $1.06(0.13)$ & 1.04 & 0.34 \\
\hline Mean $\mathrm{ABl}$ test $2 \mathrm{mmHg}$ (SD & $1.06(0.11)$ & 1.04 & 0.67 \\
\hline Mean $A B I \leq 0.90$ in both assessments & $N=3$ & $N=5$ & \\
\hline
\end{tabular}


values for the two groups (Table 1). The rates of abnormal ABI results across both testing sessions for both groups were low (diabetes $n=3$, no diabetes $n=5$ ). There were no ABI results in excess of 1.4 indicating clinically apparent medial arterial calcification in either group. The diabetes group were significantly younger and with a higher BMI than the group without diabetes. All ICCs were above the lowest acceptable ICC value as previously determined.

Intra-tester reliability results are presented in Table 2 . The intra-tester reliability of the ABI was found to be moderate to good, with an ICC value of 0.80 (95\% CI 0.70 to 0.86 ). However, sub-group analysis of participants with and without diabetes found that ABI reliability was slightly lower in participants with diabetes (ICC $0.78,95 \%$ CI 0.62 to 0.88 ) compared to those without (ICC $0.82,95 \%$ CI 0.70 to 0.90 ).

\section{Discussion}

The intraclass correlation coefficient (ICC) values obtained suggest that the intra-tester reliability of the $\mathrm{ABI}$ is good, with values that are comparable to the findings of previous studies in mixed populations including those with risk factors for and/or suspected PAD [30-32]. Similar values were obtained for the whole group (ICC 0.81 ) as well as for the group with (ICC 0.78) and without (ICC 0.82) diabetes for all analyses. The limits of agreement (LOA) that were obtained were quite large with upper and lower bounds ranging from -0.16 to 0.16 . The LOA value represents the values between which $95 \%$ of the differences between measurements fall, with differences outside of those values being more likely to represent an actual change (rather than measurement error). For this measurement, the LOA suggest that an $A B I$ value of 1.0 could vary from 0.84 to 1.16 , and not reflect an actual change in peripheral arterial supply.
Similarly, the standard error of measurement (SEM), is an estimate of how far the sample mean is likely to be from the population mean. A SEM of 0.03 demonstrates that the variability of the test means that a large change in $\mathrm{ABI}$ is required clinically for there to be certainty around it being a true change rather than variability of the measurement. This was supported by a large minimal detectable change (MDC), which reflects the amount of change required to indicate a valid change in the test result that is not due to chance [33]. The MDC was found to be 0.08 for the ABI overall, and in participants without diabetes. For the diabetes group, the MDC was 0.11. In practice, this represents a large difference between measures being required to be indicative of clinical change rather than measurement. For example, a decrease of 0.10 in ABI between measurements may represent a change from a normal value of 1.00 to 0.90 , indicating a pathological value, however where the MDC is 0.11 this change may occur as a result of measurement variability rather than disease. This finding highlights the need for the results of this test to be interpreted with caution, particularly in people with diabetes. A number of cross sectional studies have identified problems with diagnostic accuracy of the $A B I$ in specific populations, particularly those with diabetes and in older age, and have identified the need for additional testing (e.g. continuous wave Doppler, toe pressures) to be used to provide a more comprehensive evaluation of lower limb status [27, 34]. Although reliability relates to the consistency of the measurement as opposed to the accuracy, our results substantiate the need for multifaceted testing to be used as the variability of the measurement of the ABI likely further affects its effectiveness for identifying and monitoring PAD.

Our sub-analysis by diabetes status demonstrated a small reduction in ABI reliability in those with diabetes.

Table 2 Intra-tester reliability

\begin{tabular}{|c|c|c|c|c|c|c|}
\hline Measure & ICC & $95 \% \mathrm{Cl}$ & Paired t-test $\boldsymbol{p}$ value & SEM & MDC & 95\%LOA \\
\hline \multicolumn{7}{|l|}{ Whole group $(N=85)$} \\
\hline Ankle pressure & 0.89 & 0.83 to 0.92 & $<0.001$ & 2.55 & 7.07 & -8.69 to 18.22 \\
\hline Brachial Pressure & 0.77 & 0.67 to 0.84 & $<0.001$ & 3.31 & 9.17 & -12.27 to 19.12 \\
\hline$A B \mid$ & 0.80 & 0.70 to 0.86 & 0.29 & 0.03 & 0.08 & -0.14 to 0.16 \\
\hline \multicolumn{7}{|l|}{ Diabetes $(n=40)$} \\
\hline Ankle pressure & 0.92 & 0.85 to 0.96 & 0.20 & 1.84 & 5.10 & -15.07 to 10.12 \\
\hline Brachial Pressure & 0.84 & 0.72 to 0.91 & 0.26 & 2.51 & 6.96 & -13.37 to 11.12 \\
\hline$A B \mid$ & 0.78 & 0.62 to 0.88 & 0.53 & 0.04 & 0.11 & -0.16 to 0.14 \\
\hline \multicolumn{7}{|l|}{ No diabetes $(n=45)$} \\
\hline Ankle pressure & 0.88 & 0.80 to 0.93 & $<0.001$ & 2.19 & 6.07 & -6.75 to 18.35 \\
\hline Brachial Pressure & 0.74 & 0.58 to 0.85 & $<0.001$ & 4.41 & 12.22 & -11.31 to 11.12 \\
\hline$A B \mid$ & 0.82 & 0.70 to 0.90 & 0.90 & 0.03 & 0.08 & -0.15 to 0.15 \\
\hline
\end{tabular}

ICC intraclass correlation coefficient, SEM standard error of measurement, MDC minimal detectable change, LOA limits of agreement 
To the authors' knowledge, there are no published studies that evaluate $\mathrm{ABI}$ reliability in people with diabetes using ICC, with which our findings could be compared. However, published studies evaluating the intra-tester reliability of toe brachial index report similar results in people with diabetes (ICC0.72-0.75) compared to those without (ICC 0.74-0.8) [35]. The only previously published study evaluating $\mathrm{ABI}$ reliability in people with diabetes reported a coefficient of variation of $8 \%$ [21], which is similar to the standard error measurement of \pm 0.04 found in this study. Diabetes has been associated with several complications that affect diagnostic accuracy of the ABI for PAD including medial arterial calcification (MAC). It is possible such complications could affect reliability, however to our knowledge this has not yet been established. The diabetes cohort recruited to our study, although having increased risk of PAD (e.g. higher BMI, diabetes, insulin use), did not demonstrate overt clinical signs or symptoms of PAD and MAC. This cohort also had a relatively short mean duration of diabetes ( $<10$ years), making them less likely to have developed related complications. Similarly, the no diabetes group were significantly older (mean age $>75$ years) placing them at greater risk of age-related PAD and MAC but lack of abnormally low or high ABI results suggest this was not the case. This may have resulted in the similar reliability of the test in both groups.

Overall brachial pressure measurements were found to be less reliable than ankle pressure measurements in participants with and without diabetes, which is consistent with previous research using handheld Doppler in podiatry practice $[35,36]$. The use of automated oscillometric systolic blood pressure measurement has been shown to be more reliable than manual Doppler method in people with diabetes [37]. Given that ankle pressures were found to be highly reliable (ICC $0.88-0.92$ ) improving the reliability of brachial pressure measurement is likely to improve reliability of the ABI overall. Furthermore, the use of automated pressure measurement may reduce the time taken to carry out $\mathrm{ABI}$, which is one of the most frequently cited reasons not to perform vascular assessment [38]. There was a statistically significant difference in ankle pressure and brachial pressure values obtained between the first and second visit, however this was not reflected in a significant difference in the ABI result obtained. This finding may result from variation in the exact timing of the second appointment compared to the first (e.g. early in the morning for visit 1 , mid-morning for visit 2), or it may be due to familiarity with the procedure, location and researchers at the second visit.

The findings of this study should be considered in the light of the controlled conditions under which the ABI was performed, which may not reflect those under which the test is performed in clinical practice. Furthermore, all measurements were obtained manually using Doppler, and represent reliability in relation to that technique only. A further limitation is the lack of blinding of the clinician to the pressure values obtained. This study only established the intra-tester reliability of the $A B I$ when assessed by an experienced podiatrist. In clinical practice, the ABI is used by a range of health professionals, and as such the findings of this study may not be generalisable to other clinicians. In addition, the inter-rater reliability of the $\mathrm{ABI}$ is of considerable importance, considering that it is often used by different personnel rather than always being repeated by the same clinician. It is also most commonly repeated at intervals of more than 1 week, and not necessarily at the same time of day, and with patients not necessarily having avoided factors that may affect their result.

\section{Conclusions}

The results of this study suggest that while intra class correlation coefficients for the reliability of the ABI are good for people with and without diabetes, measures of the variability of the measurement suggest a large difference between tests results is required to reflect a true change. Therefore, results of the ABI should be considered in the context of other assessment of lower limb vascular status rather than in isolation. As such, our findings support the use of ABI only as part of a comprehensive vascular assessment, with the use of other techniques to form a more complete clinical picture. Further research should evaluate the inter-tester reliability of the $\mathrm{ABI}$ and using automated pressure measurement techniques.

\section{Acknowledgments}

We would like to acknowledge the participants of this study for their time.

\section{Authors' contributions}

SC and VC conceived the study and developed the methodology; SC recruited participants; SC collected data; SC and VC completed data analysis; SC, VC, and SL developed the manuscript and interpreted results, and all authors approved the final manuscript.

\section{Funding}

Funding sources include the national Research Training Scheme (Australia).

Availability of data and materials

De-identified data is held securely with the senior author.

Ethics approval and consent to participate

This research was completed under the ethical approval of the University of Newcastle Human Research Ethics Committee (H-2010-1230).

Consent for publication

Not applicable.

Competing interests

None of the authors have any conflicts of interests to declare. 


\section{Author details}

${ }^{1}$ School of Health Sciences, University of Newcastle, Ourimbah, Australia. ${ }^{2}$ Priority Research Centre for Physical Activity and Nutrition, University of Newcastle, Callaghan, Australia.

Received: 22 December 2019 Accepted: 29 April 2020

Published online: 12 May 2020

\section{References}

1. Olin JW, Sealove BA. Peripheral artery disease: current insight into the disease and its diagnosis and management. Mayo Clin Proc. 2010;85(7):678-92.

2. Ramsey SD, Newton K, Blough D, McCulloch DK, Sandhu N, Reiber GE, et al. Incidence, outcomes, and cost of foot ulcers in patients with diabetes. Diabetes Care. 1999;22(3):382-7.

3. Beckman JA, Creager MA, Libby P. Diabetes and atherosclerosis: epidemiology, pathopysiology, and management. J Am Med Assoc. 2002; 287(19):2570-81.

4. Mukherjee D, Eagle K. The importance of early diagnosis and treatment in peripheral arterial disease: insights from the PARTNERS and REACH registries. Curr Vasc Pharmacol. 2010;8(3):293-300.

5. Caruana MF, Bradbury AW, Adam DJ. The validity, reliability, reproducibility and extended utility of ankle to brachial pressure index in current vascular surgical practice. Eur J Vasc Endovasc Surg. 2005;29(5):443-51.

6. Savill P. Early diagnosis of peripheral arterial disease can save limbs. Practitioner. 2012;256(1755):19-21 2-3.

7. Aboyans V, Criqui MH, Abraham P, Allison MA, Creager MA, Diehm C, et al. Measurement and interpretation of the ankle-brachial index: a scientific statement from the American Heart Association. Circulation. 2012;126(24):2890-909.

8. Norgren L, Hiatt WR, Dormandy JA, Nehler MR, Harris KA, Fowkes FGR. Intersociety consensus for the management of peripheral arterial disease (TASC II). J Vasc Surg. 2007:45(1):S5-S67.

9. Gerhard-Herman MD, Gornik HL, Barrett C, Barshes NR, Corriere MA, Drachman DE, et al. 2016 AHA/ACC guideline on the management of patients with lower extremity peripheral artery disease: executive summary: a report of the American College of Cardiology/American Heart Association task force on clinical practice guidelines. J Am Coll Cardiol. 2016;69(11): 1465-508.

10. Norman PE, Eikelboom JW, Hankey GJ. Peripheral arterial disease: prognostic significance and prevention of atherothrombotic complications. Med J Aust. 2004;181(3):150-4.

11. Pilli R, Naidu M, Pingali U, Takallapally RK. Study of cardiovascular effects of caffeine in healthy human subjects, with special reference to pulse wave velocity using photoplethysmography. Int J Nutri Pharmacol Neurol Dis. 2012;2(3):243-50.

12. Omvik P. How smoking affects blood pressure. Blood Press. 1996;5(2):71-7.

13. Yataco AR, Gardner AW. Acute reduction in ankle/brachial index following smoking in chronic smokers with peripheral arterial occlusive disease. Angiology. 1999;50(5):355-60.

14. Carter SA. Response of ankle systolic pressure to leg exercise in mild or questionable arterial disease. N Engl J Med. 1972;287(12):578-82.

15. Georgakarakos E, Papadaki E, Vamvakerou V, Lytras D, Tsiokani A, Tsolakaki $\mathrm{O}$, et al. Training to measure ankle-brachial index at the undergraduate level: can it be successful? Int J Low Extrem Wounds. 2013;12(2):167-71.

16. Matzke S, Franckena M, Alback A, Railo M, Lepantalo M. Ankle brachial index measurements in critical leg ischaemia - the influence of experience on reproducibility. Scand J Surg. 2003;92:144-7.

17. Chuter VH, Casey SL. The effect of pre-measurement rest time on ankle systolic pressures in people with and without diabetes. Diabetologia. 2013; 56:S483-S4.

18. Pollak EW, Chavis P, Wolfman EF. The effect of postural changes upon the ankle arterial perfusion pressure. Vasc Surg. 1976;10(4):219-22.

19. Casey S, Lanting S, Oldmeadow C, Chuter V. The reliability of the ankle brachial index: a systematic review. J Foot Ankle Res. 2019;12(1). https://doi. org/10.1186/s13047-019-0350-1.

20. Baker JD, Dix DE. Variability of Doppler ankle pressures with arterial occlusive disease: an evaluation of ankle index and brachial-ankle pressure gradient. Surgery. 1981;89(1):134-7.

21. Faccenda F, Rubba P, Vaccaro O, Carbone L, Pauciullo P, Riccardi G. Reproducibility of non-invasive vascular diagnosis in patients with diabetes mellitus. Artery. 1989;16(4):189-207.
22. American Diabetes Association. Peripheral arterial disease in people with diabetes. Diabetes Care. 2003;26(12):3333-41.

23. Lowry D, Saeed M, Narendran P, Tiwari A. A review of distribution of atherosclerosis in the lower limb arteries of patients with diabetes mellitus and peripheral vascular disease. Vasc Endovasc Surg. 2018;52(7):535-42.

24. Aerden D, Massaad D, von Kemp K, van Tussenbroek F, Debing E, Keymeulen B, et al. The ankle-brachial index and the diabetic foot: a troublesome marriage. Ann Vasc Surg. 2011;25(6):770-7.

25. Ichihashi S, Hashimoto T, Iwakoshi S, Kichikawa K. Validation study of automated oscillometric measurement of the ankle-brachial index for lower arterial occlusive disease by comparison with computed tomography angiography. Hypertens Res. 2014;37(6):591-4.

26. Potier L, Abi Khalil C, Mohammedi K, Roussel R. Use and utility of ankle brachial index in patients with diabetes. Eur J Vasc Endovasc Surg. 2011;41(1):110-6.

27. Williams DT, Harding KG, Price P. An evaluation of the efficacy of methods used in screening for lower-limb arterial disease in diabetes. Diabetes Care. 2005;28(9):2206-10.

28. Walter SD, Eliasziw M, Donner A. Sample size and optimal designs for reliability studies. Stat Med. 1998;17:101-10.

29. Portney $L G$, Watkins MP. Foundations of clinical research: applications to clinical practice. 3rd ed. New Jersey: Prentice Hall; 2009.

30. Aboyans V, Lacroix P, Doucet S, Preux PM, Criqui MH, Laskar M. Diagnosis of peripheral arterial disease in general practice: can the ankle-brachial index be measured either by pulse palpation or an automatic blood pressure device? Int J Clin Pract. 2008;62:1001-7.

31. de Graaff JC, Ubbink DT, Legemate DA, de Haan RJ, Jacobs MJHM. Interobserver and intraobserver reproducibility of peripheral blood and oxygen pressure measurements in the assessment of lower extremity arterial disease. J Vasc Surg. 2001;33(5):1033-40.

32. Demir O, Tasci I, Acikel C, Saglam K, Gezer M, Acar R, et al. Individual variations in ankle brachial index measurement among Turkish adults. Vascular. 2016;24(1):53-8.

33. Haley SM, Fragala-Pinkham MA. Interpreting change scores of tests and measures used in physical therapy. Phys Ther. 2006;86(5):735-43.

34. Tehan PE, Bray A, Chuter VH. Non-invasive vascular assessment in the foot with diabetes: sensitivity and specificity of the ankle brachial index, toe brachial index and continuous wave Doppler for detecting peripheral arterial disease. J Diabetes Complicat. 2016;30(1):155-60.

35. Sonter JA, Chuter V, Casey S. Intratester and intertester reliability of toe pressure measurements in people with and without diabetes performed by podiatric physicians. J Am Podiatr Med Assoc. 2015;105(3):201-8.

36. Scanlon C, Park K, Mapletoft D, Begg L, Burns J. Interrater and intrarater reliability of photoplethysmography for measuring toe blood pressure and toe-brachial index in people with diabetes mellitus. J Foot Ankle Research 2012;5(13). http://www.ffootankleres.com/content/5/1/13.

37. Ma J, Liu M, Chen D, Wang C, Liu G, Ran X. The validity and reliability between automated oscillometric measurement of ankle-brachial index and standard measurement by eco-Doppler in diabetic patients with or without diabetic foot. Int J Endocrinol. 2017;2017:1-6.

38. Tehan PE, Chuter VH. Vascular assessment techniques of podiatrists in Australia and New Zealand: a web-based survey. J Foot Ankle Res. 2015;8(1):71.

\section{Publisher's Note}

Springer Nature remains neutral with regard to jurisdictional claims in published maps and institutional affiliations.

Ready to submit your research? Choose BMC and benefit from:

- fast, convenient online submission

- thorough peer review by experienced researchers in your field

- rapid publication on acceptance

- support for research data, including large and complex data types

- gold Open Access which fosters wider collaboration and increased citations

- maximum visibility for your research: over $100 \mathrm{M}$ website views per year

At BMC, research is always in progress.

Learn more biomedcentral.com/submission 